\title{
Is the British diet improving?
}

By David H. Buss, Ministry of Agriculture, Fisheries and Food, 65 Romney Street, London SW1P 3RD.

When I last described British dietary habits to the Nutrition Society in Reading just over 10 years ago (Buss, 1977), the factor uppermost in people's minds was the cost of food. Despite a COMA report on diet and heart disease (Department of Health and Social Security, 1974), there was comparatively little interest amongst the public about diet and health. This was perhaps not surprising, for life expectancy in Britain had been steadily increasing for many years (in 1931 it was 58 years for males and 62 years for females, but by 1971 it was 68 and 74 (and in 1984 was more than 71 and 77 years respectively) (Central Statistical Office, 1988)). The cost of food to the housewife was, however, rising dramatically, from $£ 2 /$ person per week in 1970 to $£ 3$ in $1974, £ 4$ during 1976 and $£ 5$ in 1977 . The prices of some foods doubled almost overnight, and that of sugar, when it reappeared in the shops in 1975, had tripled. Although husbands' incomes were rising at least as fast, this extra money was being spent (as now) on cars, alcohol, electrical goods, holidays and housing instead. Pressure on the Government led it to subsidize the dietary staples, whole milk, bread, butter, cheese, sugar and tea, and this helped to postpone some of the inevitable price increases.

There were also (as now) increases in the number of holidays taken abroad and of working wives, freezers, immigrants, and ethnic restaurants in Britain at that time which, together with decimalization of the currency and entry into the European Community, had been expected to have a considerable effect on people's eating habits. Yet in practice the British diet proved surprisingly resilient (Buss, 1979).

\section{Recent influences on diet}

Inflation has slowed in the 1980s, and those who worry about food have concentrated instead on the supposed health-giving or health-destroying properties of certain foods or diets. These properties have usually been related to their fat, fibre, salt, sugar or additive contents. There has, however, been less concern about eating a balanced diet to achieve adequate protein, vitamin and mineral intakes. The National Advisory Committee on Nutrition Education proposals (James, 1983) brought this to a head, for its semiquantitative suggestions struck a chord with dietitians and the media who have tended to treat them as if written on tablets of stone. They have also been over-simplified, as have those of the 1984 COMA report on dietary aspects of cardiovascular disease (Department of Health and Social Security, 1984), to be incorporated into general attacks on milk, butter, meat and meat products, sugar, white bread, convenience foods, and even on all manufactured foods, although such attacks rarely extend to, for example, wine. There has also been pressure on meats and some dairy products from the increased interest in vegetarianism, both in our indigenous population and in Britons of other ethnic origins.

While some individuals have cut back on animal products and others eat less of all foods in order to reduce weight (nearly $25 \%$ of young women claim to be watching their weight or slimming (Bull, 1985)), other young people are satisfying their enormous appetites with cheap and contemporarily-acceptable foods such as hamburgers, and fried chicken and chips, and are drinking more alcohol. At the same time, other people will be 
eating more meat, butter and other foods traditionally associated with the good life as they become richer. So what has been the overall effect of these influences on the patterns of diet throughout this country today?

\section{The changing British diet}

The best way to quantify changes in the diet throughout Britain is by means of the Ministry of Agriculture, Fisheries and Food's National Food Survey. This survey has been conducted continuously since 1940. Each year, more than 7000 nationallyrepresentative households take part, recording for one complete week the quantity and an exact description of every item of food (except for sweets and alcoholic drinks, which are measured separately) which is brought into their homes. The results, together with economic and nutritional analyses, appear in very detailed annual reports (e.g. Ministry of Agriculture, Fisheries and Food, 1987) which quantify the diets within Britain according to a wide variety of geographical and socio-economic criteria.

The illustrations in the present paper show national average food intakes for each year from 1980 to 1986 with those for 1975 presented alongside to give a longer historical perspective. Geographical differences for most of these foods are also presented in a standard format, with Scottish consumption followed by that in other regions of Britain in declining order of (male) cardiovascular mortality (even though the death rates for Scotland are lower than in the northern half of England, as shown in Table 1). The regional differences in mortality from other causes and in women follow an almost identical pattern (Table 1).

\section{Meats}

As this is a joint meeting with the British Society for Animal Production, my first illustration (Fig. 1(a)) shows the trends in carcass meat consumption. Meat and meat products, or the fat in them, have appeared on several 'hit lists' in the 1980s, in contrast to their earlier favoured position as purveyors of animal protein, iron and B-vitamins. Yet although the domestic consumption of meat and meat products together fell slightly

Table 1. Death rates per 100,000 people in Scotland* and the standard regions of England and Wales (1985) $\dagger$

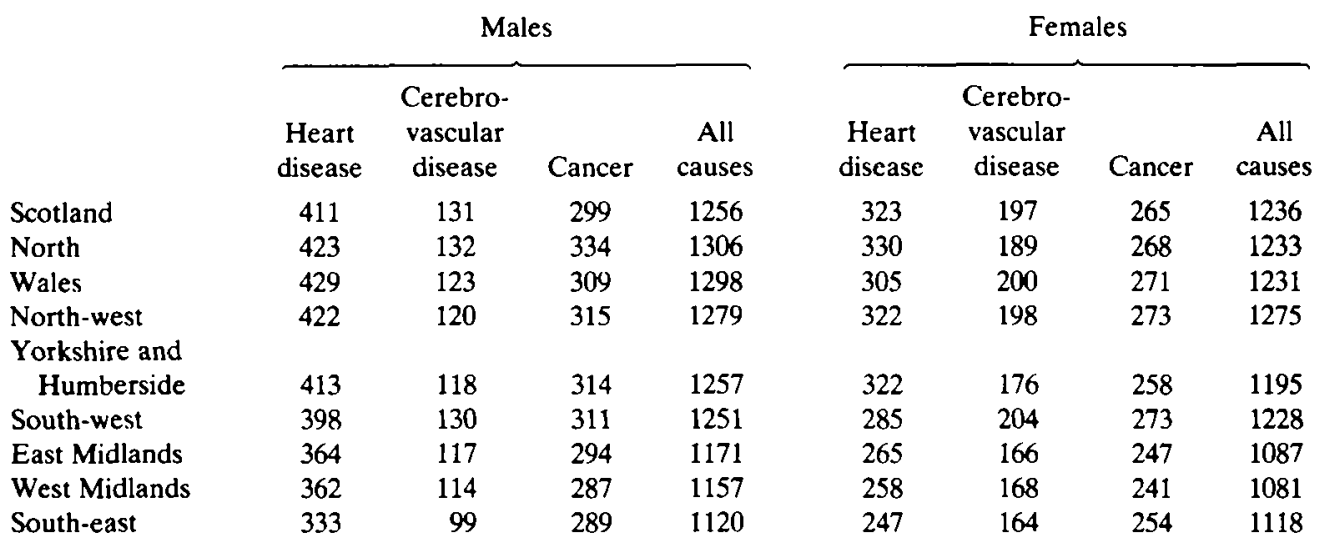

*From the General Register Office, Scotland (unpublished).

tFrom the Office of Population Censuses and Surveys (unpublished). 


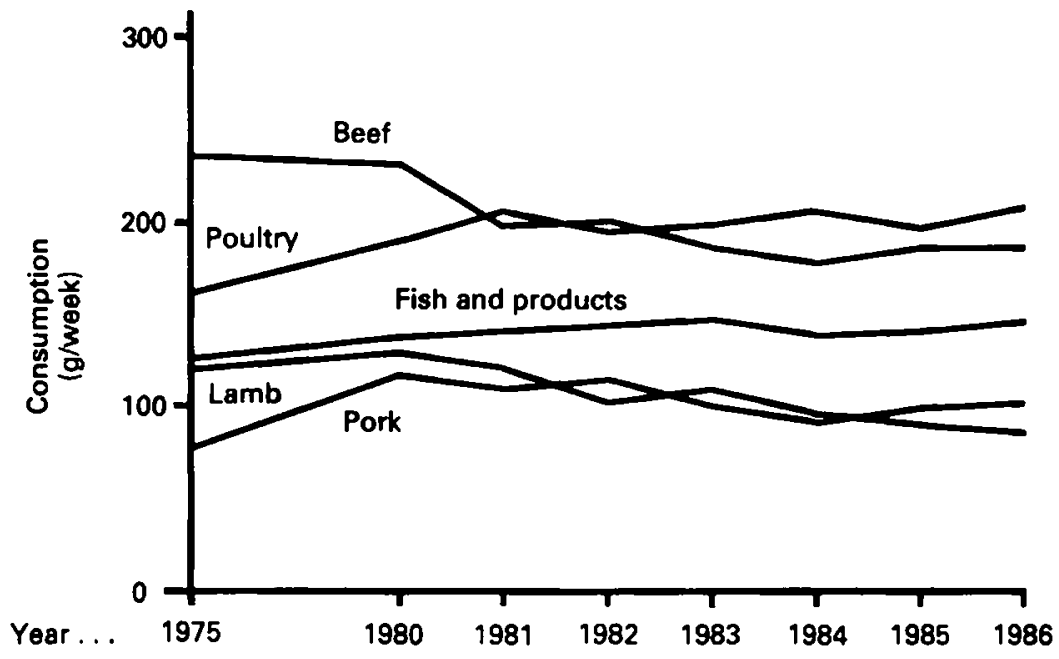

Fig. 1(a). Carcass meats and fish.

Figs. 1(a)-6(a). Trends in household consumption of selected foods in Britain. Quantities are expressed as grams or litres/person per week.

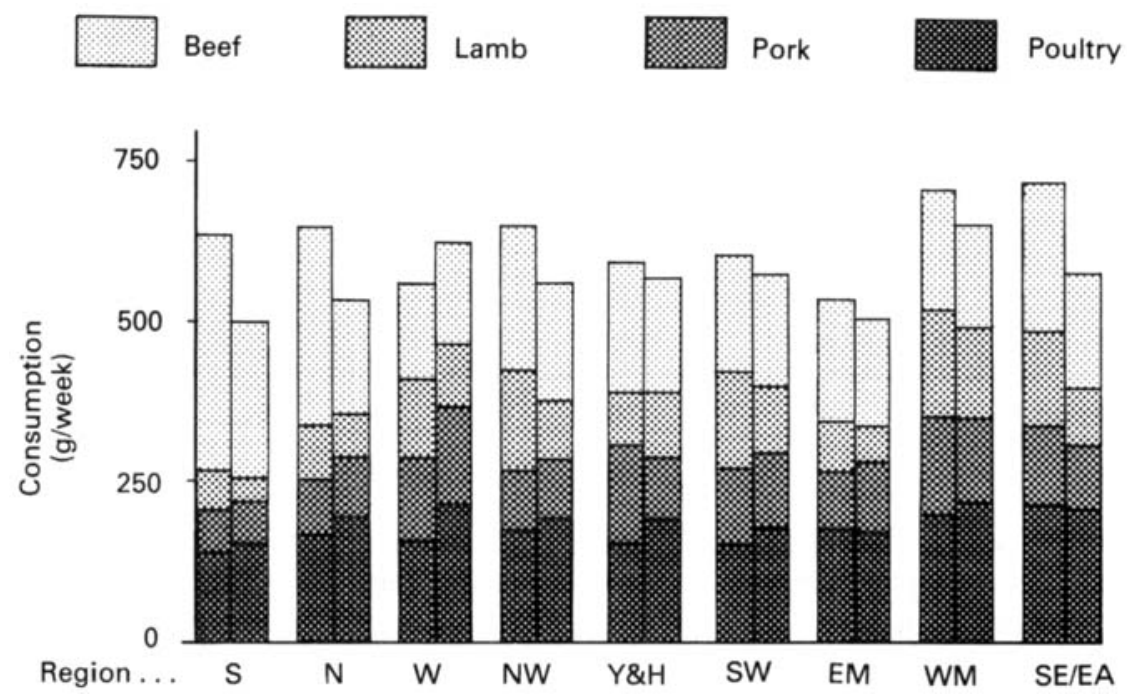

Fig. 1(b). Carcass meats.

Figs. $1(b)-6(b)$. Household consumption of selected foods in Scotland, Wales and the standard regions of England in 1980 and 1986 . The sequence of the regions is: S, Scotland; N, Northern region; W, Wales; NW, the North-west; Y\&H, Yorkshire and Humberside; SW, the South-west; EM, East Midlands; WM, West Midlands; SE/EA, South-east/East Anglia. 


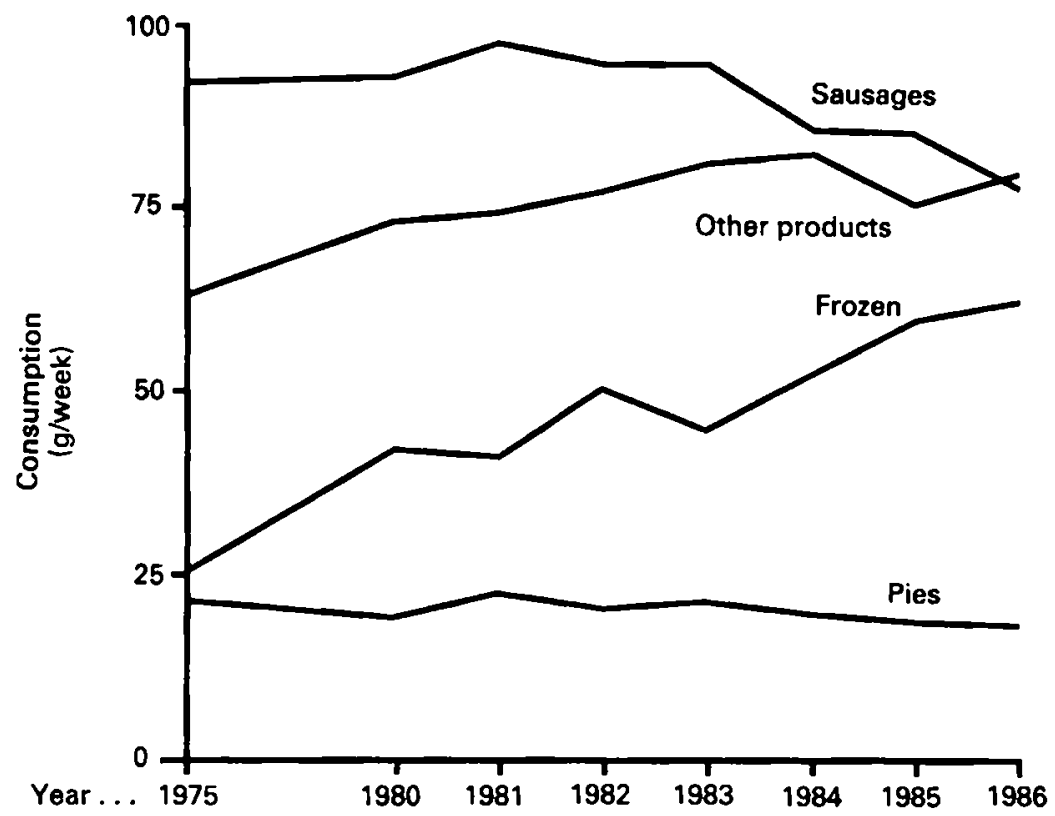

Fig. 2(a). Selected meat products.

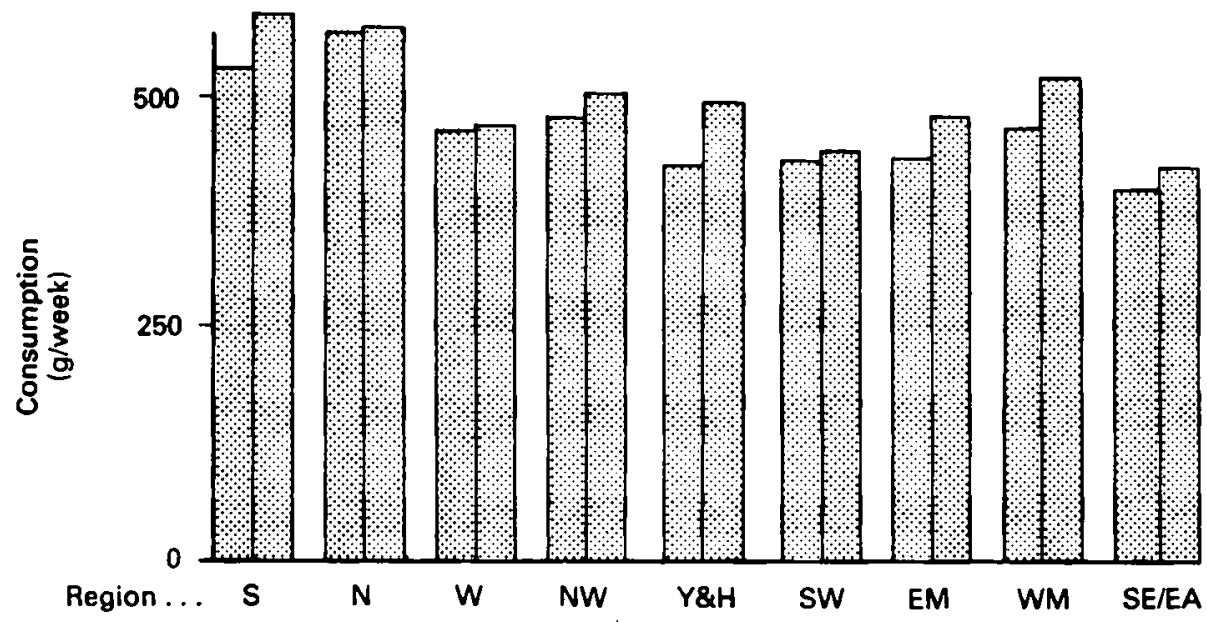

Fig. 2(b). Meat products in total.

from their high point around 1980 until 1984 , it has remained remarkably steady between about 140 and $160 \mathrm{~g} /$ person per $\mathrm{d}$ throughout the past 30 years. Within the total, however, poultry (which has been recommended on health grounds, but is also cheap) continues to gain in popularity while the preference for beef and lamb (which are getting steadily leaner but which are also comparatively expensive) has declined.

Among meat products, which remain a convenient and reasonably cheap way to fill that spot on the plate next to the potatoes and vegetables, sausages (with $20 \%$ fat or less after cooking) have clearly reacted to their adverse publicity, yet frozen products and paté, salami and other fashionable products with up to $45 \%$ fat have steadily increased in popularity (Fig. 2(a)). 
The decline in beef and lamb and increase in poultry have occurred in almost every region (Fig. 1(b)) although traditional preferences, such as for beef over lamb in Scotland, remain. Similarly, the regional differences in meat product consumption have remained as the increases have occurred everywhere (Fig. 2(b)).

\section{Milks}

After some 25 years of steady sales, milk consumption started to decline in the late 1970s, perhaps because of the rise in alternative drinks such as 'low-calorie' and other soft drinks and fruit juices. Much of that decline is now being offset by the increasingly

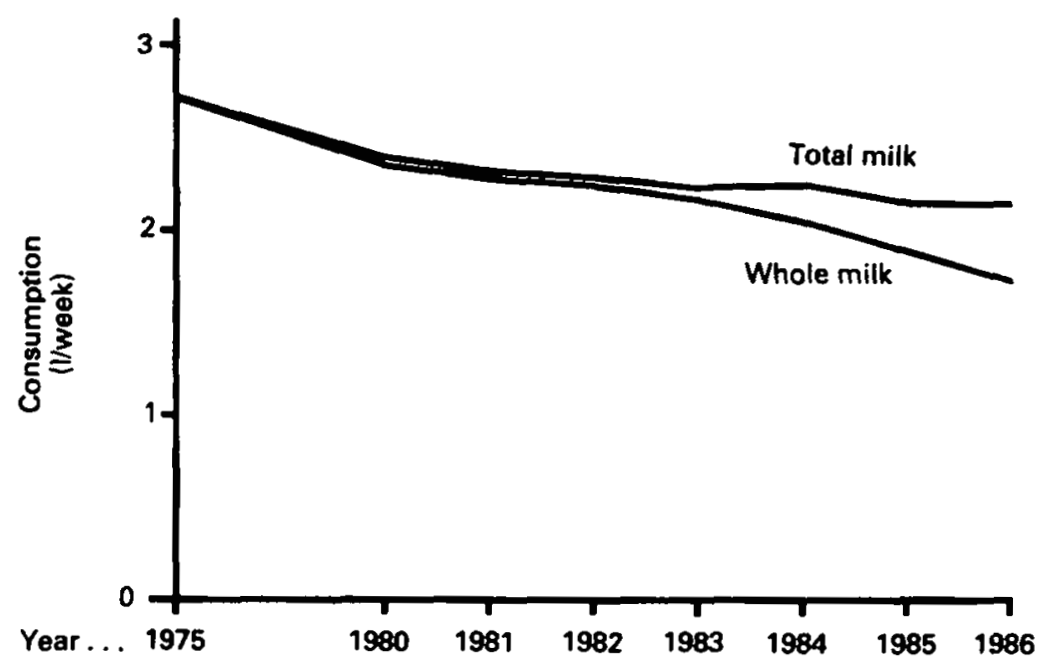

Fig. 3(a). Liquid milk and whole milk.

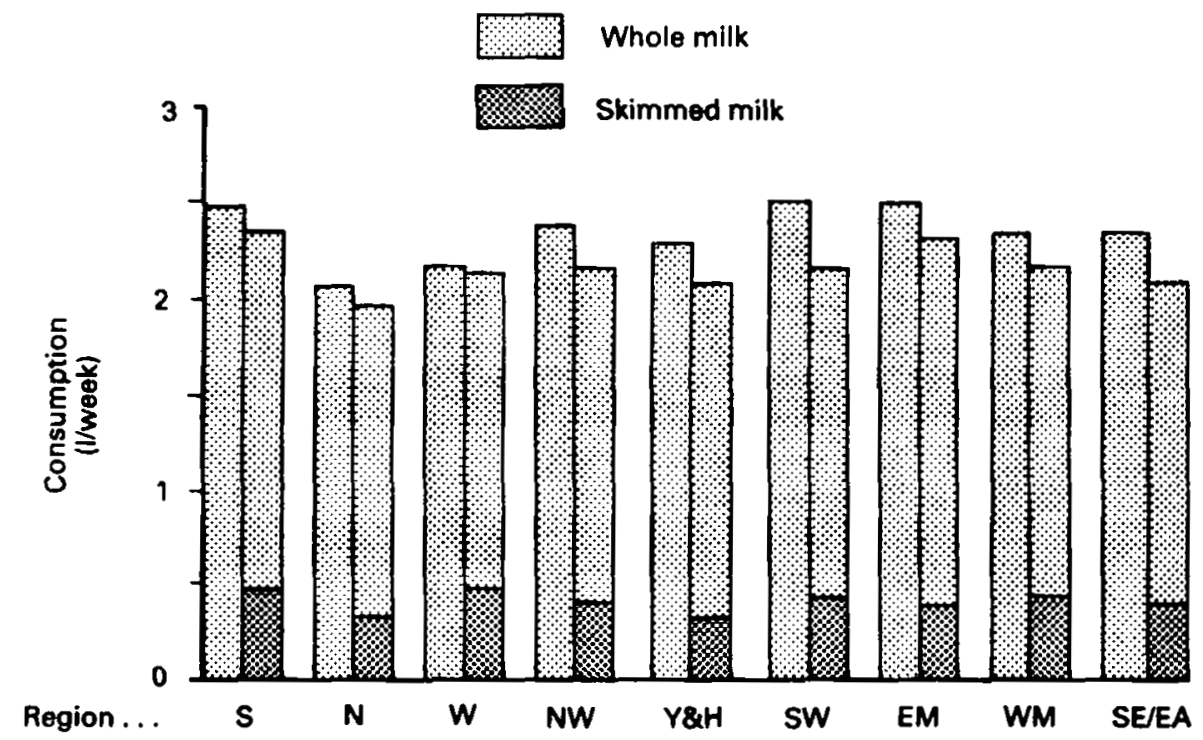

Fig. 3(b). Whole milk and skimmed milk. 
popular skimmed and semi-skimmed milks which were hardly available before 1983 . These now meet over $15 \%$ of the liquid-milk market (Fig. 3(a)), and offer one of the very few examples of major dietary trends that were not apparent 10 or even 20 years ago, but which began in response to the new interest in health. Yoghurt consumption has grown steadily in the home as elsewhere over the past 20 years (doubling between 1975 and 1980 and doubling again since then) as it is a convenient, varied and supposedly healthy milk product, while cheese consumption has remained at about $110 \mathrm{~g} /$ person per week.

Very similar changes have occurred almost simultaneously in all regions, although skimmed milks and milk in total are not as popular in the North of England as elsewhere (Fig. 3(b)).

\section{Fats}

Visible fat consumption has remained between about 300 and $350 \mathrm{~g} /$ person per week throughout the past 40 years, but in the 1980s the British preference for butter has increasingly been replaced not so much by margarine in total (Fig. 4(a)) as by soft and polyunsaturated margarines whose spreadability makes them more convenient products. Such margarines are also cheaper than butter, and have been promoted as 'healthier' even if it is the diet as a whole that really matters. On the other hand, hard margarine which is used primarily for home baking is even cheaper but its consumption has altered little, and a health image had not much effect on the use of vegetable oil until recently (although consumption of 'low-fat' spreads has increased substantially, albeit from a low base). It may, I think, be deduced from this and other examples that more than one clear advantage has to be perceived before there can be marked national dietary changes.

Similar trends in visible fat consumption have occurred in all the regions. Purchases remain lowest in Scotland, and there are no marked differences between the other regions (Fig. $4(b)$ ) to correspond to their differences in mortality.

\section{Sugars}

Sugar and sugary foods have been a particular target of many nutritionists, and domestic usage of packet sugar has declined in recent years (Fig. 5(a)). Indeed, the national supplies of sugar have declined steadily since the end of the upsurge in the 1950 s following the deprivations of the Second World War. Part of this decline may relate to a concern about obesity, but may also be from the decline in many of its traditional uses in home baking, in tea and coffee (which are now often drunk unsweetened or with artificial sweeteners), jam making, and in the nearly defunct home-bottling of fruit. On the other hand, sugar is increasingly used with breakfast cereals, and the consumption of sugary foods such as the convenient commercial cakes and biscuits continues much as before. So too does the consumption of confectionery, especially chocolate.

Domestic sugar purchases are declining everywhere, but remain lowest in the urban South-east. They are also lower in Wales, the North and Scotland than in the Midlands (Fig. 5(b)), in part perhaps because households which buy more pre-packaged cakes and biscuits tend to buy less sugar per se.

\section{Breads}

One of the most marked trends in recent years has been the increased popularity of wholemeal bread (Fig. $6(a)$ ). Domestic consumption of bread as a whole had fallen 


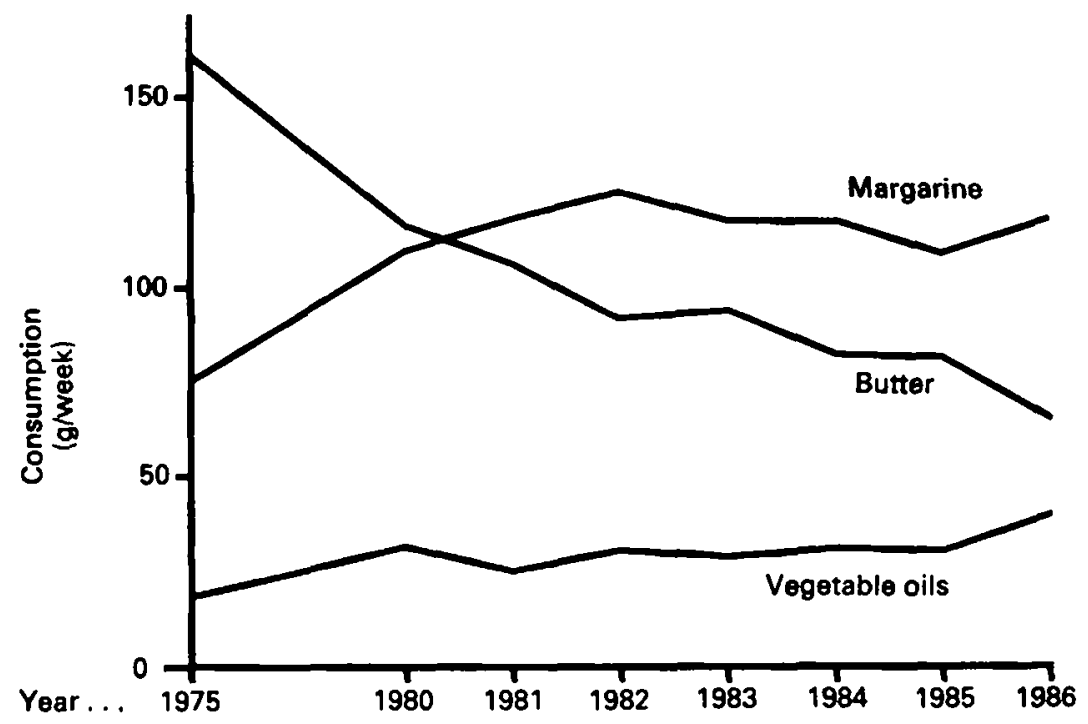

Fig. $4(a)$. Butter, margarine and vegetable oils.

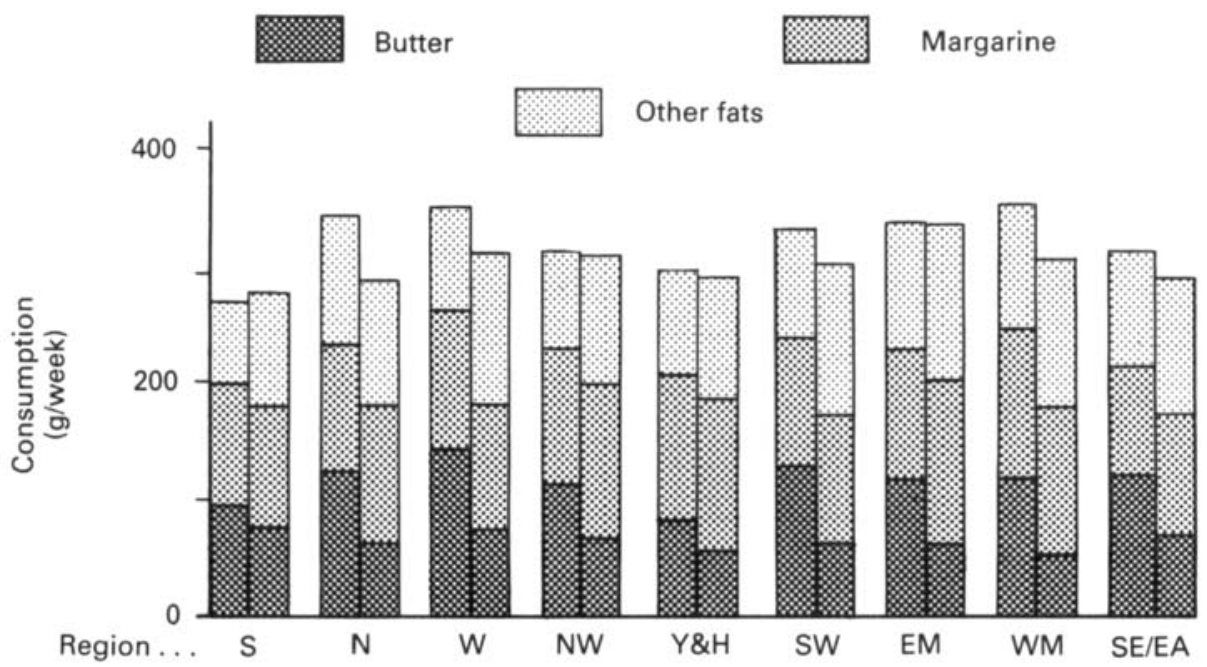

Fig. 4(b). Butter, margarine and all other visible fats.

continuously between 1950 and 1980, but has now steadied almost entirely because of sales of this much-promoted but also much-improved bread (even if it still constitutes only about one-sixth of the total bread market). In contrast, white bread, which also has useful amounts of fibre and whose consumption has been recommended by the Department of Health and Social Security (1981), continues to decline. Rice and pasta consumption, while increasing, remain at less than $25 \mathrm{~g} /$ person per week on average, and their whole-grain products are not popular.

Regionally, bread is eaten least in the south-east and most in the Midlands, the North and Scotland (Fig. 6(b)). There are no clear geographical trends in the consumption of 


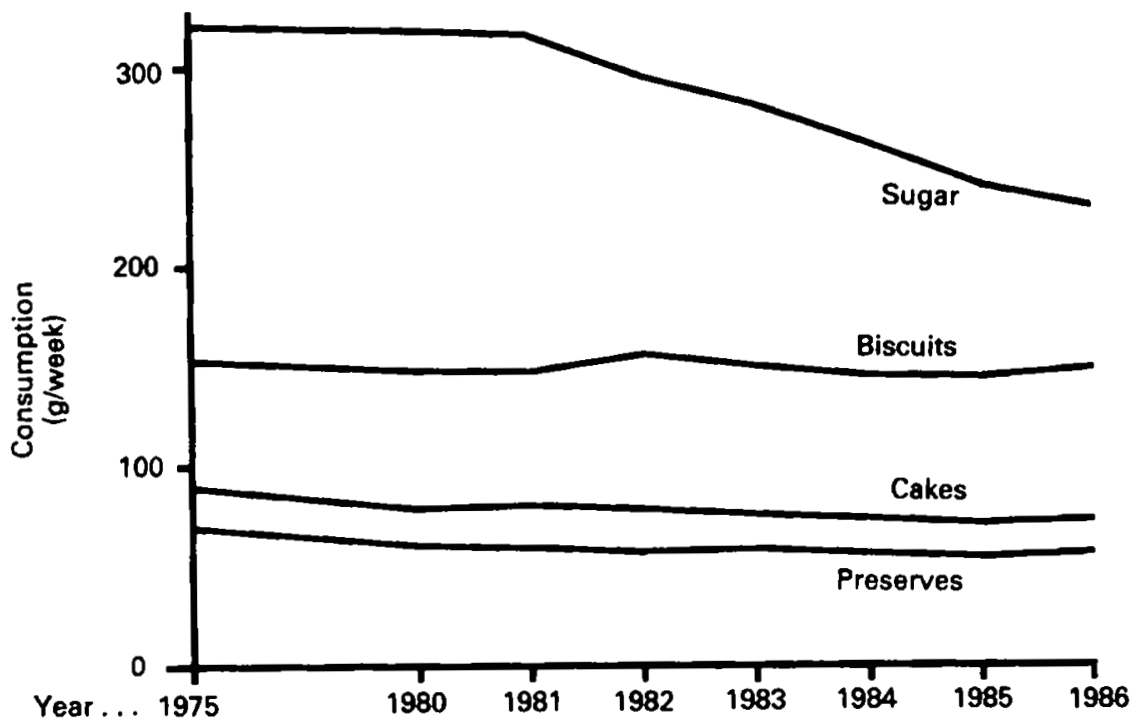

Fig. 5(a). Packet sugar and sugar-containing foods.

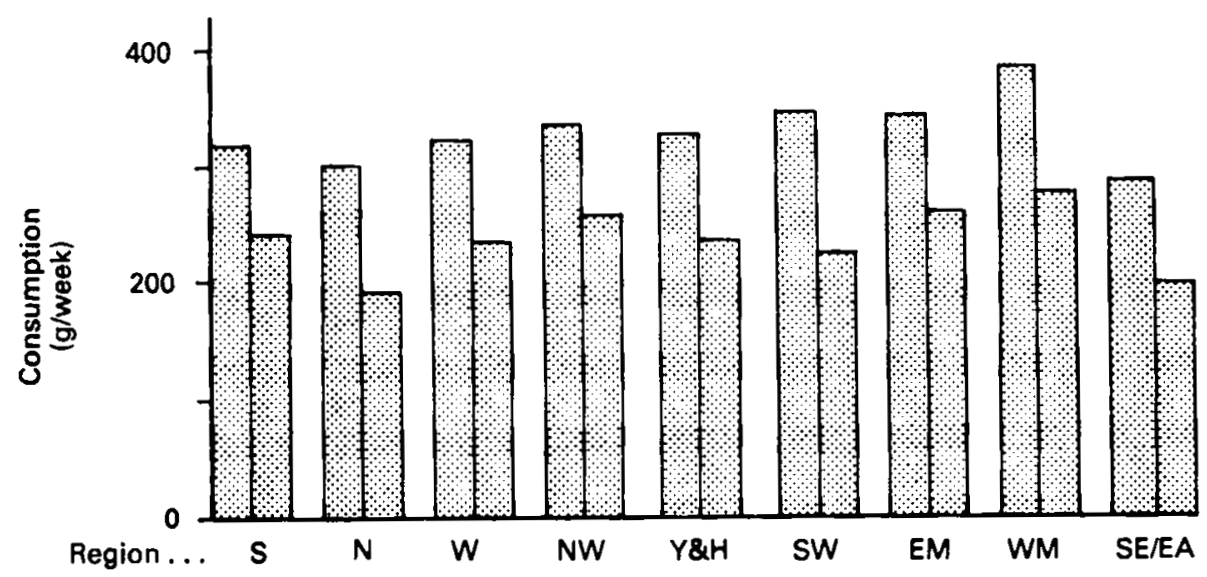

Fig. 5(b). Packet sugar.

bread as a whole, but that of wholemeal bread is increasing everywhere, while remaining most popular in Wales and the South of England.

\section{Other trends}

A number of these dietary trends have been in conformity with recent health advice, even though additional persuasive reasons for change seem to be necessary to make most of them occur (Buss, 1987). Thus, a food which offered health without pleasure or convenience would almost certainly achieve no more than transitory sales, yet the opposite does not necessarily follow in that chocolate (Fig. 7) and alcoholic drink consumption (Fig. 8) continue to increase steadily. And our fresh fruit and vegetable consumption remain among the lowest in the developed world. 


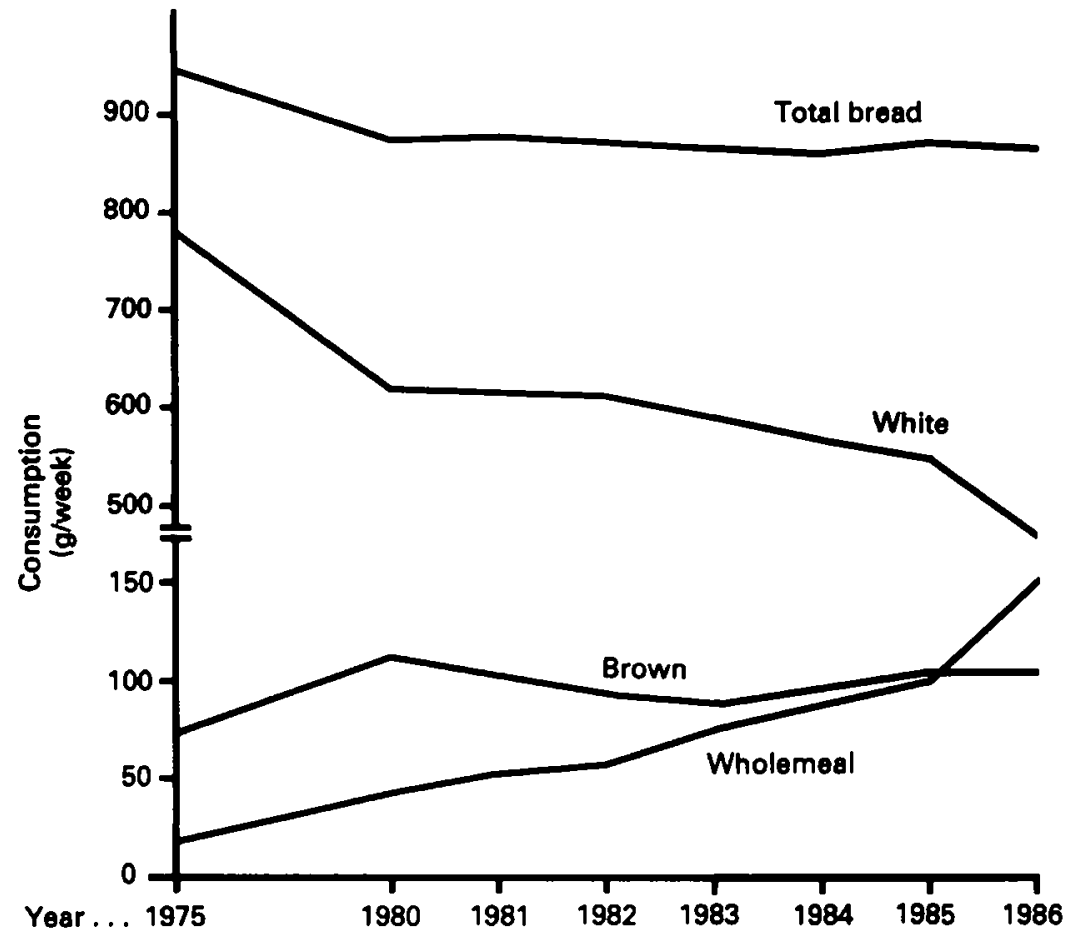

Fig. 6(a). Bread.

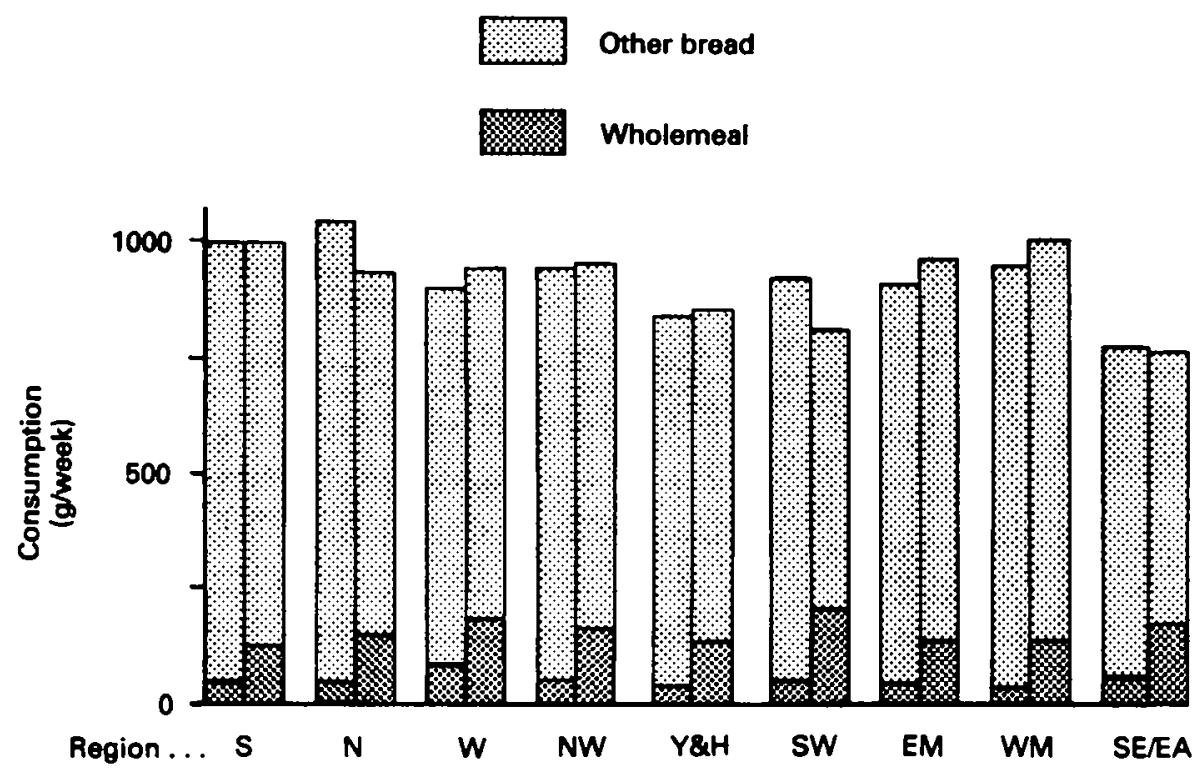

Fig. 6(b). Wholemeal and all other bread. 


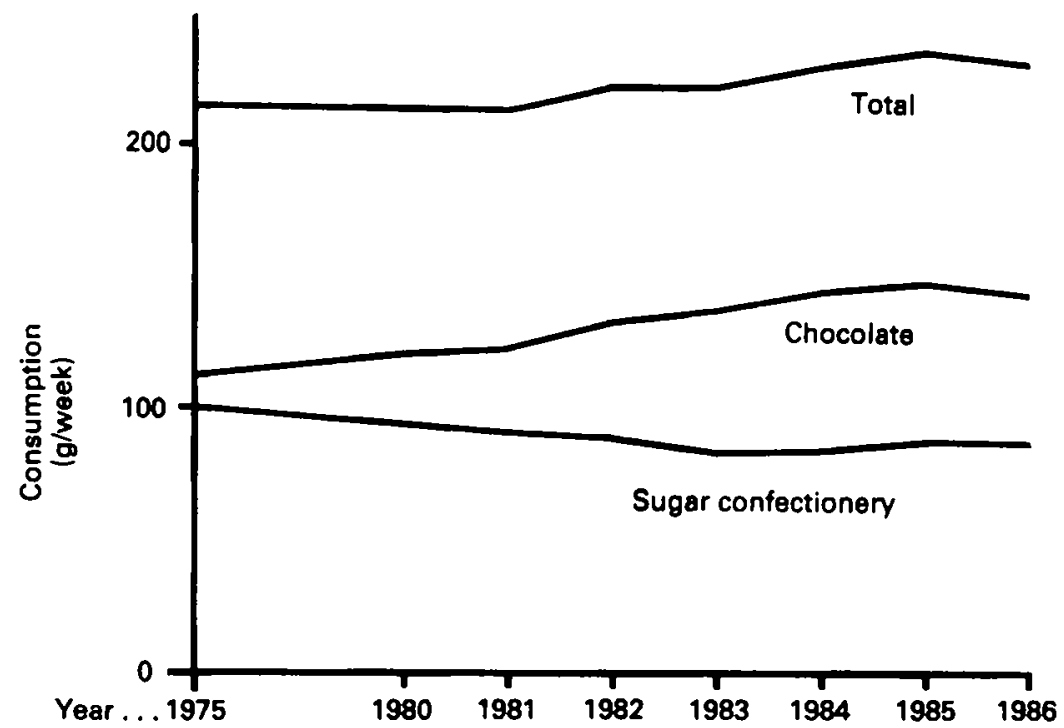

Fig. 7. National supplies of sweets.

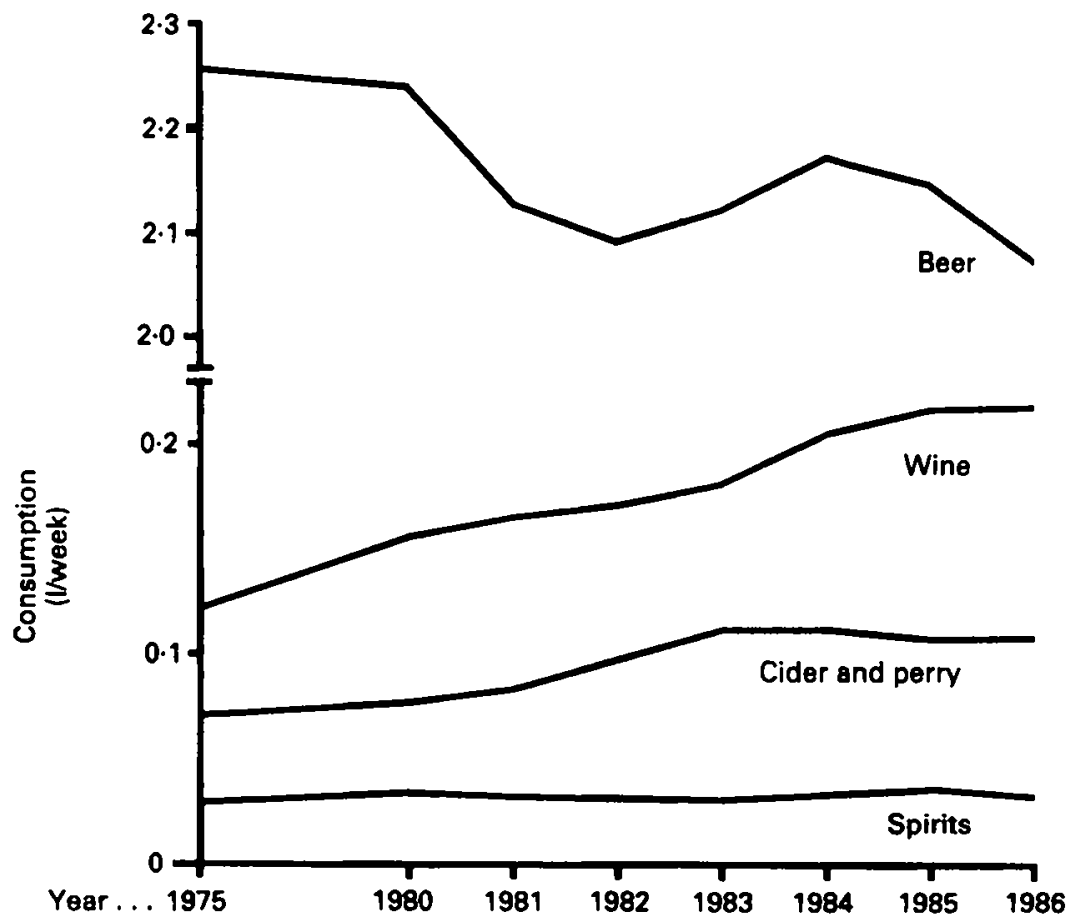

Fig. 8. National supplies of alcoholic drinks. 


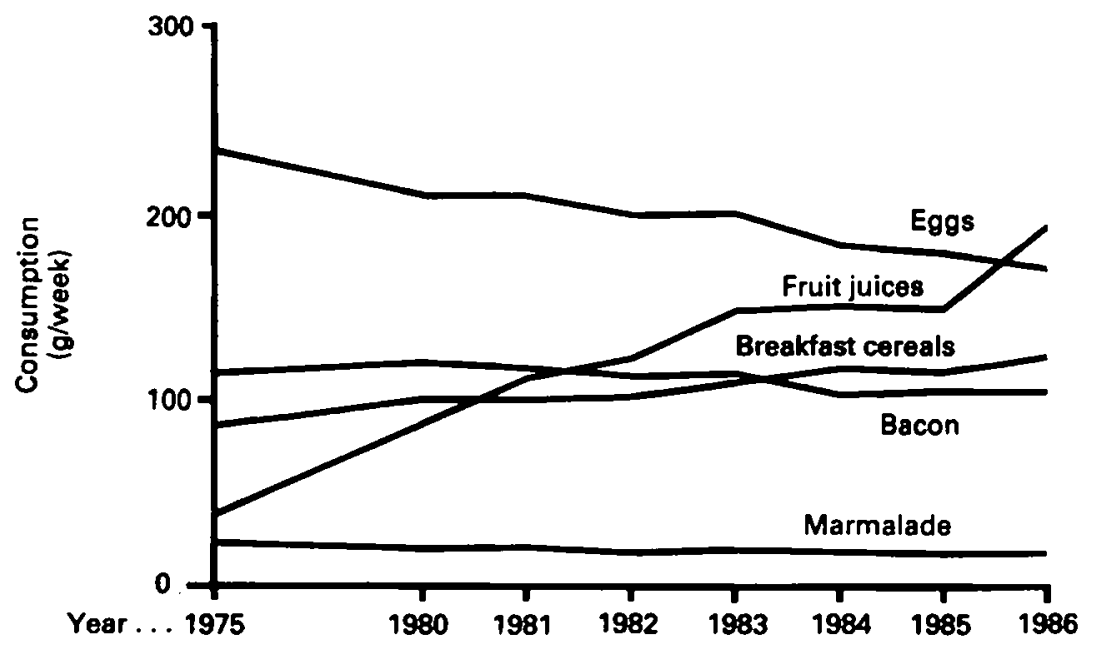

Fig. 9. Foods commonly eaten at breakfast.

A different example of continuing dietary change which may have gained impetus from the new health interests is illustrated in Fig. 9 and is the decline in the traditional British breakfast of bacon and eggs to (if anything is eaten at all) breakfast cereals and most recently to fruit juices. There are, however, yet other important fashions and pressures for change which have few if any nutritional overtones. For example, the widespread desire for convenience without loss of good taste has resulted in a rapid growth of all types of frozen food including frozen meat products, chips, ice-cream and fish fingers, to parallel the increased ownership of freezers (3\% of households had one in $1970,23 \%$ by $1975,46 \%$ by 1980 , and nearly $70 \%$ now) and of microwave ovens ( $20 \%$ of households now owning one).

\section{Nutritional conclusions}

Although convenience, fashion, the changing age and ethnic structure of our population, price and many other factors are, as always, important in changing dietary patterns, there are now clear signs that perceived relations with health are also having a marked influence on some aspects of the British diet in all the regions of Britain. This should have pleased the media, as well as nutritionists and dietitians, whose aim in promoting many of these changes was to reduce the prevalence of coronary heart disease. But COMA's recommendations were for an individual's consumption of saturated (plus trans) fatty acids to provide no more than $15 \%$ of his food energy and for total fat to provide no more than $35 \%$ of this energy (Department of Health and Social Security, 1984). Have the changes actually had this effect?

Table 2 shows that the changes described in the present paper have substantially reduced total fat consumption in the home in almost every region of Britain. However, because they have also reduced sugar and energy intakes there has been remarkably little effect on the proportion of food energy derived from fat or from saturated fatty acids. Indeed, the proportion of energy from fat has increased in several of the regions. On the other hand, the ratio of polyunsaturated:saturated fatty acids has increased dramatically everywhere. 
Table 2. Characteristics of the fat in household diets in the standard regions of Britain

\begin{tabular}{|c|c|c|c|c|c|c|}
\hline & \multicolumn{2}{|c|}{ g/person per d } & \multicolumn{2}{|c|}{$\%$ of energy } & \multicolumn{2}{|c|}{$P: S$} \\
\hline & 1980 & 1986 & 1980 & 1986 & 1980 & 1986 \\
\hline Scotland & 102 & 98 & $40 \cdot 8$ & $42 \cdot 0$ & 0.23 & 0.33 \\
\hline North & 110 & 99 & 42.0 & 41.9 & 0.23 & 0.35 \\
\hline Wales & 109 & 101 & $42 \cdot 8$ & $42 \cdot 3$ & 0.22 & 0.34 \\
\hline North-west & 104 & 98 & $42 \cdot 3$ & $42 \cdot 7$ & 0.23 & 0.35 \\
\hline Yorkshire and Humberside & 99 & 97 & $42 \cdot 2$ & $42 \cdot 5$ & 0.25 & 0.35 \\
\hline South-west & 108 & 99 & $42 \cdot 8$ & $43 \cdot 4$ & 0.22 & 0.35 \\
\hline East Midlands & 104 & 103 & $42 \cdot 4$ & $42 \cdot 4$ & 0.24 & 0.36 \\
\hline West Midlands & 112 & 101 & $41 \cdot 8$ & $42 \cdot 1$ & 0.26 & 0.36 \\
\hline South-east/East Anglia & 105 & 96 & 43.6 & $42 \cdot 9$ & 0.25 & 0.36 \\
\hline
\end{tabular}

P:S, polyunsaturated:saturated fatty acids.

Other nutrients in the domestic food supply have changed, too, and not always for the better (Table 3). Many of these nutrients also show more regional variation than does fat. Nevertheless, we must hope that the overall effect of the dietary changes in this country, which broadly follow those recommended so widely, is soon to bring some real reduction in cardiovascular and other mortalities lest the reputation of nutritionists begins to decline even faster than some of these foods!

Table 3. Selected nutrients in household diets in the standard regions of Britain

\begin{tabular}{|c|c|c|c|c|c|c|}
\hline & \multicolumn{2}{|c|}{ Calcium (mg/d) } & \multicolumn{2}{|c|}{ Vitamin $C(\mathrm{mg} / \mathrm{d})$} & \multicolumn{2}{|c|}{$\beta$-Carotene $(\mu \mathrm{g} / \mathrm{d})$} \\
\hline & 1980 & 1986 & 1980 & 1986 & 1980 & 1986 \\
\hline Scotland & 960 & 900 & 52 & 52 & 1860 & 1840 \\
\hline North & 940 & 900 & 53 & 60 & 2140 & 2300 \\
\hline Wales & 1010 & 910 & 62 & 59 & 2670 & 2230 \\
\hline North-west & 930 & 870 & 52 & 52 & 2610 & 2230 \\
\hline Yorkshire and Humberside & 920 & 860 & 52 & 52 & 2300 & 2270 \\
\hline South-west & 990 & 900 & 56 & 63 & 2360 & 2130 \\
\hline East Midlands & 970 & 950 & 53 & 57 & 2260 & 2150 \\
\hline West Midlands & 990 & 910 & 54 & 57 & 2130 & 2130 \\
\hline South-east/East Anglia & 950 & 890 & 66 & 67 & 2520 & 2170 \\
\hline
\end{tabular}

\section{REFERENCES}

Bull, N. L. (1985). Human Nutrition: Applied Nutrition 39A, Suppl. 1, 1-68.

Buss, D. H. (1977). Proceedings of the Nutrition Society 36, 247-253.

Buss, D. H. (1979). Journal of Human Nutrition 33, 47-55.

Buss, D. H. (1987). In Food and Health - Now and the Future, pp. 139-152 [R. Cottrell, editor]. Carnforth, Lancs.: Parthenon Publishing Group.

Central Statistical Office (1988). Social Trends 18. London: H.M. Stationery Office.

Department of Health and Social Security (1974). Diet and Coronary Heart Disease. London: H.M. Stationery Office.

Department of Health and Social Security (1981). Nutritional Aspects of Bread and Flour. London: H.M. Stationery Office.

Department of Health and Social Security (1984). Diet and Cardiovascular Disease. London: H.M. Stationery Office.

James, W. P. T. (1983). Proposals for Nutritional Guidelines for Health Education in Britain. London: Health Education Council.

Ministry of Agriculture, Fisheries and Food (1987). Household Food Consumption and Expenditure: 1986. London: H.M. Stationery Office. 